\title{
Use of Lambda-Mu-Sigma-Derived Z Score for Evaluating Respiratory Impairment in Middle-Aged Persons
}

\author{
Carlos A Vaz Fragoso MD, Thomas M Gill MD, Gail McAvay PhD, Peter H Van Ness PhD, \\ $\mathrm{H}$ Klar Yaggi MD, and John Concato MD
}

\begin{abstract}
BACKGROUND: The lambda-mu-sigma (LMS) method calculates the lower limit of normal for spirometric values as the 5 th percentile of the distribution of $\mathbf{Z}$ scores. Conceptually, LMS-derived $\mathbf{Z}$ scores account for normal age-related changes in pulmonary function, including variability and skewness in reference data. Evidence is limited, however, on whether the LMS method is valid for evaluating respiratory impairment in middle-aged persons. OBJECTIVE: To evaluate the association of LMS-defined respiratory impairment (airflow limitation and restrictive pattern) with mortality and respiratory symptoms. METHODS: We analyzed spirometric data from white participants ages 45-64 years in the Third National Health and Nutrition Examination Survey (NHANES III, $n=1,569$ ) and the Atherosclerosis Risk in Communities study (ARIC, $n=8,163$ ). RESULTS: LMS-defined airflow limitation was significantly associated with mortality (adjusted hazard ratios: NHANES III 1.90, 95\% CI 1.32-2.72, ARIC 1.28, 95\% CI 1.06-1.57), and respiratory symptoms (adjusted odds ratios: NHANES III 2.48, 95\% CI 1.75-3.51, ARIC 2.27, 95\% CI 1.98-2.62). LMS-defined restrictive-pattern was also significantly associated with mortality (adjusted hazard ratios: NHANES III 1.98, 95\% CI 1.08-3.65, ARIC 1.38, 95\% CI 1.03-1.85), and respiratory symptoms (adjusted odds ratios: NHANES III 2.34, 95\% CI 1.44-3.80, ARIC 1.89, 95\% CI 1.46-2.45). CONCLUSIONS: In white middle-age persons, LMS-defined airflow limitation and restrictive-pattern were significantly associated with mortality and respiratory symptoms. Consequently, an approach that reports spirometric values based on LMS-derived $\mathrm{Z}$ scores might provide an age-appropriate and clinically valid strategy for evaluating respiratory impairment. Key words: spirometry; airflow limitation; restrictive-pattern; mortality; respiratory symptoms. [Respir Care 2011;56(11):1771-1777. () 2011 Daedalus Enterprises]
\end{abstract}

\section{Introduction}

In aging populations, because of widespread and cumulative exposure to tobacco smoke, respiratory infections, occupational dust, and air pollution, the evaluation of re-

Drs Vaz Fragoso, Yaggi, and Concato are affiliated with the Clinical Epidemiology Research Center, Veterans Affairs Connecticut Healthcare System, West Haven, Connecticut. Drs Vaz Fragoso, Gill, McAvay, Van Ness, Yaggi, and Concato are affiliated with the Department of Internal Medicine, Yale University School of Medicine, New Haven, Connecticut.

Dr Vaz Fragoso was partly supported by a Department of Veterans Affairs Career Development Award and National Institute on Aging award R03AG037051. Dr Gill was partly supported by an National Institutes of Health Midcareer Investigator Award in Patient-Oriented Research K24AG021507. Dr Yaggi was partly supported by a Career Development Transition Award from the Department of Veterans Affairs spiratory impairment has clinical and epidemiological implications. ${ }^{1-4}$ Most often, respiratory impairment is established spirometrically, as airflow limitation (eg, COPD or asthma) and restrictive-pattern (eg, thoracic kyphosis, heart failure, or interstitial lung disease).,5 Importantly, to minimize misidentification of respiratory impairment and to better inform clinical decision making, it is imperative that

\footnotetext{
Clinical Science Research and Development Service. Dr Concato was partly supported by the Department of Veterans Affairs Cooperative Studies Program. The authors have disclosed no other conflicts of interest.

Correspondence: Carlos A Vaz Fragoso MD, Clinical Epidemiology Research Center, Veterans Affairs Connecticut Healthcare System, 950 Campbell Avenue, Mail Code 151B, West Haven CT. E-mail: carlos.fragoso@yale.edu.
}

DOI: $10.4187 /$ respcare.01192 
spirometric diagnostic thresholds consider normal age-related changes in pulmonary function and health outcomes. ${ }^{6-14}$

Developmentally, after achieving peak pulmonary function at about 20 years of age, spirometry values progressively decrease with age, principally due to increasing rigidity of the chest wall and decreasing elastic recoil of the lung. ${ }^{7-10}$ In addition, between-subject differences in spirometric performance also increases progressively in adults, starting at about age 30 years. ${ }^{8,9}$ Accordingly, to account for normal age-related changes in pulmonary function, the lambda-mu-sigma (LMS) method has been proposed as a basis for establishing spirometric diagnostic thresholds..$^{8,9}$ Specifically, the LMS method calculates the lower limit of normal as the 5th percentile of the distribution of $\mathrm{Z}$ scores (LMS $\mathrm{LLN}_{5}$ ), analogous to current strategies for reporting bone mineral density testing. ${ }^{8,9,15}$ Conceptually, LMS-derived Z scores include: the median (mu), which represents how spirometry variables change based on predictor variables (age and height); the coefficient of variation (sigma), which models the spread of reference values and adjusts for non-uniform dispersion; and skewness (lambda), which models departure from normality. ${ }^{8,9}$ The LMS method substantially improves the calculation of spirometric Z scores, compared to previous calculations based on conventional multiple regression. ${ }^{11,12}$ Multiple regression has potential limitations, because it uses inadequate methods for modeling the relationships between predictor variables and spirometric variables, including incorrectly assuming that reference values are distributed normally and have constant variability across an individual's lifespan. ${ }^{8,9}$

\section{See the Related Editorial on Page 1861}

Beyond the strong mathematical rationale, the LMS LLN $_{5}$ threshold may also have "clinical validity," namely a documented association with health outcomes, as a basis for establishing respiratory impairment. ${ }^{13,14}$ Specifically, with spirometric data from a large cohort of middle-age (40-64 years) and older-age (65-80 years) persons, prior work evaluated different $\mathrm{Z}$ score thresholds for the ratio of $\mathrm{FEV}_{1}$ to $\mathrm{FVC}$ and found that the upper limit that was associated with significantly higher risk was the LMS $\mathrm{LLN}_{5} .{ }^{13}$ That study was based on a single cohort, however, and did not specifically evaluate the clinical validity of LMS-defined airflow limitation and restrictivepattern, relative to normal pulmonary function-a diagnostic process that requires consideration of both $\mathrm{FVC}$ and $\mathrm{FEV}_{1} / \mathrm{FVC}$ (see Methods section). ${ }^{6}$ Thus, it remained to be seen whether the LMS method is appropriate for evaluating respiratory impairment in middle-age and older persons.

In the present study we analyzed LMS-derived Z scores for spirometry data from 2 large cohorts of community- living middle-aged persons, to evaluate the association of respiratory impairment with mortality and respiratory symptoms. We also calculated the frequency of misidentification of respiratory impairment with the current spirometric criteria, relative to LMS-based assessment of respiratory impairment.

\section{Methods}

This study was approved by the institutional review boards of Veterans Affairs Connecticut Healthcare System and Yale University School of Medicine. The study was conducted at the Yale Claude D Pepper Older Americans Independence Center and the Clinical Epidemiology Research Center, Veterans Affairs Connecticut Healthcare System, West Haven, Connecticut.

\section{Study Population}

We used de-identified, publically available data from the Third National Health and Nutrition Examination Survey (NHANES III) and Atherosclerosis Risk in Communities study (ARIC). ${ }^{16,17} \mathrm{We}$ included only white, middleage (45-64 years) participants, because LMS reference values are currently unavailable for non-whites and because of the age range of ARIC participants. ${ }^{8,9,17} \mathrm{We}$ analyzed only data from participants who had completed at least 2 spirometry maneuvers acceptable by the American Thoracic Society/European Respiratory Society (ATS/ ERS) criteria, at initial baseline examination. Per current convention, we did not exclude participants based on spirometric reproducibility criteria. ${ }^{18}$ To focus on "irreversible" pathology, participants with self-reported asthma were excluded.

NHANES III was designed to provide national estimates of the health and nutritional status of the United States non-institutionalized population. ${ }^{16}$ The NHANES III sample, assembled in 1988-1994 and followed through 2000 , used a complex design to generate a nationally representative sample, with an age range of 8-80 years $(n=33,994) .{ }^{16}$ Based on eligibility criteria, our study sample from NHANES III included 1,569 participants. ARIC was a population-based, longitudinal study of middle-age persons, assembled in 1986-1989 as a probability sample from 4 United States communities and followed through 1998, with an age range of 45-64 years $(n=15,732) .{ }^{17}$ Based on eligibility criteria, our study sample from ARIC included 8,163 participants.

\section{Spirometry}

In both study samples, participants underwent spirometry during their baseline examination, according to the contemporary ATS protocol, ${ }^{19}$ with equipment that met 
ATS accuracy requirements (a dry rolling-seal spirometer in NHANES III, and a water-seal spirometer in ARIC). ${ }^{16,17}$ With each subject, $\mathrm{FEV}_{1} / \mathrm{FVC}$ was calculated from the largest set of $\mathrm{FEV}_{1}$ and $\mathrm{FVC}$ values from maneuvers that met the ATS acceptability criteria. ${ }^{18,19}$

In both study samples, based on measured values for each participant and as recommended, we calculated LMSderived $\mathrm{Z}$ scores for $\mathrm{FEV}_{1} / \mathrm{FVC}$ and $\mathrm{FVC}$ as:

$$
\left[(\text { measured/median predicted })^{\text {lambda }}-1\right] /(\text { lambda } \times \text { sigma })
$$

A Z score of -1.64 corresponded to the $\operatorname{LMS~LLN~}_{5}{ }^{8,9}$ We used the LMS prediction equations to calculate values for the median, lambda, and skewness. We obtained cubic splines for age from tables at http://www.lungfunction.org/growinglungs/software.html. Those tables are based on 4 pooled reference samples with age range $4-80$ years. ${ }^{8}$ Using the LMS $\mathrm{LLN}_{5}$ as a diagnostic threshold, and per current convention, we classified participants as having normal pulmonary function if both $\mathrm{FEV}_{1} / \mathrm{FVC}$ and FVC were $\geq$ LMS LLN ${ }_{5}$, airflow limitation if $\mathrm{FEV}_{1} / \mathrm{FVC}$ was $<$ LMS $\mathrm{LLN}_{5}$, or restrictive-pattern if $\mathrm{FEV}_{1} / \mathrm{FVC}$ was $\geq$ LMS LLN $_{5}$ and FVC was $<$ LMS $\operatorname{LLN}_{5}{ }^{5,6,8,8,11-13}$

We also classified each subject's respiratory status based on current Global Initiative for Obstructive Lung Disease (GOLD) and ATS/ERS spirometric criteria. GOLD advocates a fixed $\mathrm{FEV}_{1} / \mathrm{FVC}$ of 0.70 and an $\mathrm{FVC}$ of $80 \%$ of predicted. ${ }^{5,20}$ The ATS/ERS recommend the 5th percentile of the distribution of reference values as the LLN cut-point for both $\mathrm{FEV}_{1} / \mathrm{FVC}$ and FVC (ATS/ERS LLN $\left.{ }_{5}\right) .{ }^{6}$ Based on those thresholds, GOLD defines normal pulmonary function as an $\mathrm{FEV}_{1} / \mathrm{FVC} \geq 0.70$ and an $\mathrm{FVC} \geq 80 \%$ of predicted, airflow limitation as an $\mathrm{FEV}_{1} / \mathrm{FVC}<0.70$, and restrictive-pattern as an $\mathrm{FEV}_{1} / \mathrm{FVC} \geq 0.70$ and $\mathrm{FVC}<80 \%$ of predicted. ${ }^{5,20} \mathrm{We}$ calculated percent of predicted as: [measured/predicted] $\times 100$ with predicted values derived from published regression equations.., 21

ATS/ERS defines normal pulmonary function as both $\mathrm{FEV}_{1} / \mathrm{FVC}$ and $\mathrm{FVC} \geq \mathrm{ATS} / \mathrm{ERS} \mathrm{LLN}_{5}$, airflow limitation as $\mathrm{FEV}_{1} / \mathrm{FVC}<\mathrm{ATS} / \mathrm{ERS} \mathrm{LLN}_{5}$, and restrictivepattern as $\mathrm{FEV}_{1} / \mathrm{FVC} \geq \mathrm{ATS} / \mathrm{ERS} \mathrm{LLN}_{5}$ and $\mathrm{FVC}<\mathrm{ATS} /$ ERS $\mathrm{LLN}_{5} \cdot{ }^{6}$ The ATS/ERS $\mathrm{LLN}_{5}$ threshold was derived from published regression equations..$^{21}$

\section{Clinical Variables}

We recorded baseline clinical characteristics, including age, sex, height, body mass index, self-reported chronic conditions, health status, and smoking history. ${ }^{16,17}$ Respiratory symptoms were also evaluated, including:

- Chronic cough or sputum production, defined by a yes response to either of the questions, "Do you usually cough on most days for 3 consecutive months or more during the year?" or "Do you bring up phlegm on most days for 3 consecutive months or more during the year?" (NHANES III and ARIC)

- Dyspnea on exertion, defined by a yes response to the question, "Are you troubled by shortness of breath when hurrying on the level or walking up a slight hill?" (NHANES III and ARICS)

- Wheezing, defined by a yes response to the question, "Have you had wheezing or whistling in your chest at any time in the past 12 months?" (NHANES III) or "Does your chest ever sound wheezy or whistling, apart from colds?" (ARIC). ${ }^{16,17}$

All-cause mortality was recorded in NHANES III, based on the National Death Index, with a median follow-up of 9.2 years (IQR 7.5-10.5 y). ${ }^{22}$ ARIC recorded all-cause mortality based on annual telephone calls, hospital surveillance, vital statistics databases, and the National Death Index, with median follow-up of 11.0 years (IQR 10.9-11.1). ${ }^{17}$

\section{Statistical Analysis}

Baseline characteristics of each study sample were first summarized as mean \pm SD or as counts and percentages. We analyzed the association between LMS-defined respiratory impairment and death with Cox regression models, adjusted for baseline clinical characteristics, including age, height, sex, ethnicity, smoking history, body mass index, number of chronic conditions, and health status. LMSdefined airflow limitation and restrictive-pattern were treated as nominal categories, and the reference group was participants with normal pulmonary function. With each Cox regression model, goodness-of-fit was assessed with model-fitting procedures and analysis of residuals. We tested the proportional hazards assumption with interaction terms for the time-to-event outcome and each variable in the multivariable model; the terms were retained if $P<.05$ after adjusting for the multiplicity of comparisons. We tested higher-order effects for the continuous covariates and included them in the final model if they met the forward selection criterion of $P<.20 .{ }^{23}$ Similarly, we evaluated the association between LMS-defined respiratory impairment and the presence of respiratory symptoms by calculating odds ratios with logistic regression models.

We also calculated the prevalence of respiratory impairment according to the GOLD, ATS/ERS, and LMS criteria, as well as determined the frequency of misidentified respiratory impairment (false positive and false negative) with the GOLD and ATS/ERS criteria, relative to the LMSbased assessment.

We used statistics software (SUDAAN 10, RTI International, Research Triangle Park, North Carolina, and SAS 9.2, SAS Institute, Cary, North Carolina) for all the analyses. A 2-sided $P<.05$ was considered statistically significant. ${ }^{24,25}$ 
Table 1. Baseline Characteristics and Mortality

\begin{tabular}{|c|c|c|}
\hline & $\begin{array}{l}\text { NHANES III } \\
(n=1,569)\end{array}$ & $\begin{array}{c}\text { ARIC } \\
(n=8,163)\end{array}$ \\
\hline Age (mean \pm SD y) & $54.7 \pm 5.8$ & $54.1 \pm 5.7$ \\
\hline Female, no. $(\%)$ & $813(51.8)$ & $4,376(53.6)$ \\
\hline Body mass index $\left(\right.$ mean $\left.\pm \mathrm{SD} \mathrm{kg} / \mathrm{m}^{2}\right)$ & $27.7 \pm 5.4$ & $27.0 \pm 4.8$ \\
\hline \multicolumn{3}{|l|}{ Smoking status, no. (\%) } \\
\hline Never & $603(38.4)$ & $3,077(37.7)$ \\
\hline Former & $552(35.2)$ & $2,934(36.0)$ \\
\hline Current & $414(26.4)$ & $2,143(26.3)$ \\
\hline Chronic conditions $($ mean $\pm \mathrm{SD}) *$ & $0.6 \pm 0.8$ & $0.6 \pm 0.7$ \\
\hline Self-reported COPD, no. $(\%) \dagger$ & $131(8.4)$ & $756(9.3)$ \\
\hline Fair-to-poor health status, no. (\%) & $254(16.2)$ & 929 (11.4) \\
\hline \multicolumn{3}{|l|}{ Outcomes } \\
\hline Respiratory symptoms, no. $(\%) \ddagger$ & $627(40.0)$ & $3,102(39.6)$ \\
\hline Deaths, no. $(\%) \S$ & $132(8.4)$ & $677(8.3)$ \\
\hline Mortality rate (per 1,000 person-years) & 9.4 & 7.8 \\
\hline \multicolumn{3}{|c|}{$\begin{array}{l}\text { * Self-reported, physician-diagnosed. } \\
\dagger \text { Based on self-reported, physician-diagnosed chronic bronchitis or emphysema. } \\
\text { † Included chronic cough or sputum production, dyspnea on exertion, or wheezing (see } \\
\text { methods section). Missing data: NHANES III } 1 \text { patient }(<1 \%) \text {, ARIC } 325 \text { patients }(4.0 \%) \text {. } \\
\S \text { Vital status data were available from all participants. } \\
\text { NHANES III = Third National Health and Nutrition Examination Survey } \\
\text { ARIC = Atherosclerosis Risk in Communities study }\end{array}$} \\
\hline
\end{tabular}

\section{Results}

Table 1 describes the participants. Overall, the NHANES II and ARIC samples were similar in age, female representation, body mass index, smoking status, frequency of chronic conditions, self-reported COPD, and respiratory symptoms. However, the NHANES III participants had a greater proportion of self-reported fair-topoor health status ("reduced health") and a higher mortality rate.

Table 2 shows the hazard ratios for all-cause mortality. Airflow limitation had an adjusted hazard ratio for mortality of 1.90 (95\% CI 1.32-2.72) and 1.28 (95\% CI 1.06$1.57)$ in the NHANES III and ARIC groups, respectively. Restrictive-pattern had an adjusted hazard ratio for mortality of 1.98 (95\% CI 1.08-3.65) and 1.38 (95\% CI 1.031.85 ) in the NHANES III and ARIC groups, respectively.

Table 3 shows the odds ratios for respiratory symptoms. Airflow limitation had an adjusted odds ratio for respiratory symptoms of 2.48 (95\% CI 1.75-3.51) and 2.27 (95\% CI 1.98-2.62) in the NHANES III and ARIC groups, respectively. Restrictive-pattern had an adjusted odds ratio for respiratory symptoms of 2.34 (95\% CI 1.44-3.80) and 1.89 (95\% CI 1.46-2.45) in the NHANES III and ARIC groups, respectively.

Table 4 shows the prevalence of respiratory impairment. For airflow limitation, GOLD yielded the highest frequencies (NHANES III 22.2\%, ARIC 21.6\%), ATS/ERS yielded the second highest frequencies (NHANES III 17.3\%,
ARIC 15.8\%), and LMS yielded the lowest frequencies (NHANES III 15.7\%, ARIC 14.3\%). For restrictive-pattern, ATS/ERS yielded the highest frequencies (NHANES III $10.8 \%$, ARIC 5.7\%), GOLD yielded the second highest frequencies (NHANES III 9.5\%, ARIC 4.9\%), and LMS yielded the lowest frequencies (NHANES III 7.2\%, ARIC 3.9\%).

Table 5 shows the percentages of misidentified respiratory impairment. GOLD substantially misidentified normal pulmonary function as respiratory impairment (false positives), with frequencies of $27.9 \%$ and $33.6 \%$ for airflow limitation, and frequencies of $29.2 \%$ and $27.6 \%$ for restrictive-pattern, in the NHANES III and ARIC groups, respectively. ATS/ERS also misidentified normal pulmonary function as respiratory impairment, but predominantly for restrictive-pattern, with frequencies of $34.7 \%$ and $31.4 \%$, and uncommonly for airflow limitation, with frequencies of $9.0 \%$ and $9.5 \%$, in NHANES III and ARIC, respectively. Otherwise, GOLD and ATS/ERS infrequently misidentified respiratory impairment as normal (false negatives), with a frequency range of $0.4-2.6 \%$ for airflow limitation and a frequency range of $1.6-10.8 \%$ for restrictive-pattern.

\section{Discussion}

LMS-defined airflow limitation and restrictive-pattern were associated with a significantly higher risk of death and likelihood of having respiratory symptoms. Moreover, relative to LMS, we also found that the current GOLD and ATS/ERS spirometric criteria may misidentify normal pulmonary function as airflow limitation or restrictive-pattern. These results support the use of LMS-derived Z scores for evaluating spirometry data in middle-aged persons.

Evaluating respiratory impairment based on the LMS method has a strong mathematical and clinical rationale. ${ }^{8,9,13-15}$ LMS-derived $\mathrm{Z}$ scores account for age-related changes in pulmonary function, including variability and skewness in reference data. ${ }^{8,9}$ We found that LMSderived $\mathrm{Z}$ score thresholds for spirometric variables were also associated with important health outcomes. All-cause mortality is an objective and definitive outcome that is resistant to miscoding and was the primary end point in landmark studies of oxygen therapy. ${ }^{26}$ In addition, respiratory symptoms are the most distressing feature of respiratory disease and can lead to disability and increased healthcare utilization. ${ }^{26,27}$ Although lacking specificity, the use of respiratory symptoms as a basis for establishing validation recognizes their importance in clinical decisions, as evident in practice guidelines from GOLD, ATS/ERS, and the American College of Physicians.5,28,29

Our results also quantify how often the currently accepted spirometric criteria may misidentify respiratory impairment in middle-aged persons (see Table 5). For exam- 


\section{LAMBdA-Mu-Sigma-Derived Z SCORE For Evaluating ResPiratory IMPairment}

Table 2. Hazard Ratios for All-Cause Mortality

\begin{tabular}{|c|c|c|c|c|}
\hline \multirow[t]{2}{*}{ Lambda-Mu-Sigma-Defined Spirometry Category* } & \multirow{2}{*}{$\begin{array}{l}\text { Participants } \\
\text { no. }(\%)\end{array}$} & \multirow{2}{*}{$\begin{array}{c}\text { Deaths Among Participants } \\
\text { no. }(\%)\end{array}$} & \multicolumn{2}{|c|}{$\begin{array}{l}\text { Hazard Ratio for All-Cause Mortality } \\
\qquad(95 \% \mathrm{CI}) \dagger\end{array}$} \\
\hline & & & Unadjusted & Adjusted \\
\hline \multicolumn{5}{|l|}{ NHANES III $(n=1,548) \ddagger$} \\
\hline Normal pulmonary function & $1,194(77.1)$ & $75(6.3)$ & 1.00 & 1.00 \\
\hline Airflow limitation & $243(15.7)$ & $38(15.6)$ & $2.63(1.90-3.63)$ & $1.90(1.32-2.72)$ \\
\hline Restrictive-pattern & $111(7.2)$ & $16(14.4)$ & $2.61(1.51-4.50)$ & $1.98(1.08-3.65)$ \\
\hline \multicolumn{5}{|l|}{ ARIC $(n=7,972) \S$} \\
\hline Normal pulmonary function & $6,516(81.7)$ & $465(7.1)$ & 1.00 & \\
\hline Airflow limitation & $1,142(14.3)$ & $138(12.1)$ & $1.63(1.35-1.97)$ & $1.28(1.06-1.57)$ \\
\hline Restrictive-pattern & $314(3.9)$ & $54(17.2)$ & $2.32(1.75-3.08)$ & $1.38(1.03-1.85)$ \\
\hline \multicolumn{5}{|c|}{ 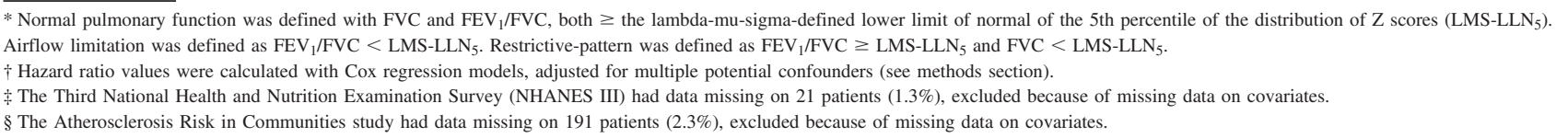 } \\
\hline
\end{tabular}

Table 3. Odds Ratios for Respiratory Symptoms

\begin{tabular}{|c|c|c|c|c|}
\hline \multirow{2}{*}{ Lambda-Mu-Sigma-Defined Spirometry Category* } & \multirow{2}{*}{$\begin{array}{l}\text { Participants } \\
\text { no. (\%) }\end{array}$} & \multirow{2}{*}{$\begin{array}{l}\text { Participants With } \\
\text { Respiratory Symptoms } \\
\text { no. }(\%)\end{array}$} & \multicolumn{2}{|c|}{$\begin{array}{l}\text { Odds Ratio for Respiratory Symptoms } \\
\qquad(95 \% \mathrm{CI}) \dagger\end{array}$} \\
\hline & & & Unadjusted & Adjusted \\
\hline \multicolumn{5}{|l|}{ NHANES III $(n=1,547) \ddagger$} \\
\hline Normal pulmonary function & $1,193(77.1)$ & $404(33.9)$ & 1.00 & 1.00 \\
\hline Airflow limitation & $243(15.7)$ & $147(60.5)$ & $2.99(2.16-4.13)$ & $2.48(1.75-3.51)$ \\
\hline Restrictive-pattern & $141(9.6)$ & $84(59.6)$ & $3.33(2.10-5.30)$ & $2.34(1.44-3.80)$ \\
\hline \multicolumn{5}{|l|}{ ARIC $(n=7,658) \S$} \\
\hline Normal pulmonary function & $6,253(81.6)$ & $2,213(35.4)$ & 1.00 & \\
\hline Airflow limitation & $1,113(14.5)$ & $622(55.9)$ & $2.31(2.03-2.63)$ & $2.27(1.98-2.62)$ \\
\hline Restrictive-pattern & $292(3.8)$ & $175(59.9)$ & $2.73(2.15-3.47)$ & $1.89(1.46-2.45)$ \\
\hline \multicolumn{5}{|c|}{ 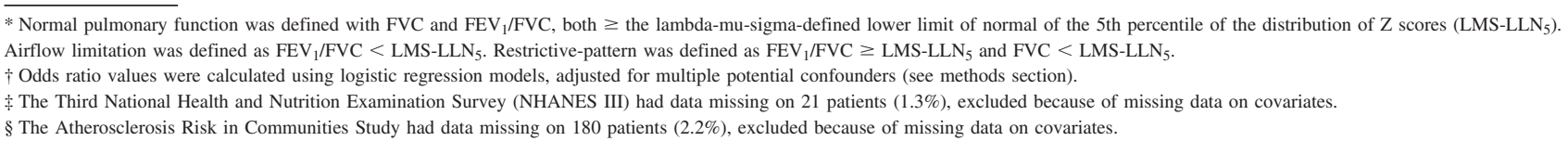 } \\
\hline
\end{tabular}

ple, based on LMS-based assessment, the GOLD criteria frequently misidentified normal pulmonary function as airflow limitation or restrictive-pattern. Although they yielded assessments of airflow limitation that were similar to LMS, the ATS/ERS criteria nonetheless frequently misidentified normal pulmonary function as restrictive-pattern.

The misidentification of respiratory impairment by current spirometric criteria may reflect age-related methodological limitations. ${ }^{6-14}$ Specifically, the GOLD thresholds for $\mathrm{FEV}_{1} /$ FVC (0.70) and FVC (80\% of predicted) have methodological weaknesses in adults, for at least 2 reasons. First, because normal aging is associated with increased chest-wall rigidity and loss of elastic recoil of the lung, normal aging often leads to an $\mathrm{FEV}_{1} / \mathrm{FVC}<0.70$, starting at about $40-50$ years of age. ${ }^{6-14}$ Second, spirometric performance shows increasing variability starting at about 30 years of age, which moves the 80\%-of-predicted cut-point for FVC away from the LLN. ${ }^{6-14}$ The ATS/ERS LLN $_{5}$ threshold for $\mathrm{FEV}_{1} / \mathrm{FVC}$ and FVC is also potentially flawed, principally because it does not adequately account for the age-related increased variability and skewness in spirometric reference data..$^{8,9,13}$ This means that the ATS/ERS LLN is based only on the distribution of reference values, whereas the LMS LLN is based on a $\mathrm{Z}$ score that additionally accounts for variability in spirometric performance and skewness of reference data. ${ }^{8} 9$ Importantly, as shown in prior work, ${ }^{8,9,13}$ these age-related methodological limitations become progressively worse with advancing age and, hence, should be the focus of future work on the spirometric definition of respiratory impairment in people $\geq 65$ years old.

Whether the potential misidentification of respiratory impairment with the GOLD and ATS/ERS criteria, relative 


\section{LAMBdA-Mu-Sigma-Derived Z SCORE For Evaluating ResPiratory IMPAIRMENT}

Table 4. Prevalence of Respiratory Impairment

\begin{tabular}{|c|c|c|c|c|}
\hline & \multicolumn{2}{|c|}{ Airflow Limitation, no. (\%) } & \multicolumn{2}{|c|}{ Restrictive-Pattern, no. (\%) } \\
\hline & $\begin{array}{l}\text { NHANES III } \\
(n=1,548\end{array}$ & $\begin{array}{c}\text { ARIC } \\
(n=7,972\end{array}$ & $\begin{array}{l}\text { NHANES III } \\
(n=1,548\end{array}$ & $\begin{array}{c}\text { ARIC } \\
(n=7,972\end{array}$ \\
\hline GOLD* & $344(22.2)$ & $1,723(21.6)$ & $147(9.5)$ & $387(4.9)$ \\
\hline $\mathrm{ATS} / \mathrm{ERS} \dagger$ & $268(17.3)$ & $1,256(15.8)$ & $167(10.8)$ & $452(5.7)$ \\
\hline Lambda-mu-sigma & $243(15.7)$ & $1,142(14.3)$ & $111(7.2)$ & $314(3.9)$ \\
\hline \multicolumn{5}{|c|}{ 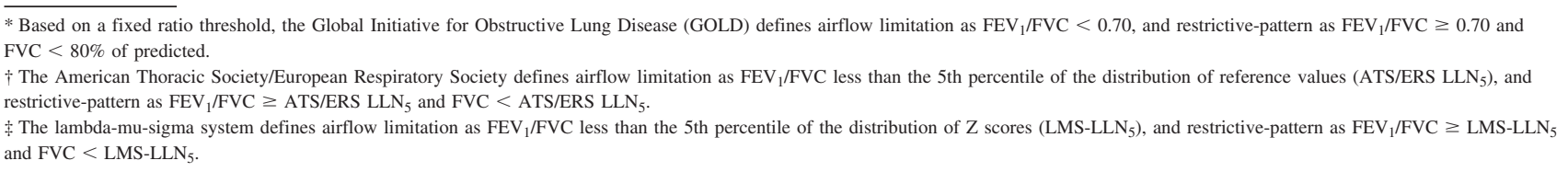 } \\
\hline
\end{tabular}

Table 5. Misidentified Respiratory Impairment by GOLD and ATS/ERS Criteria, Relative to Lambda-Mu-Sigma Criteria

\begin{tabular}{|c|c|c|c|c|}
\hline & \multicolumn{2}{|c|}{ False Positive Airflow Limitation, no. (\%)* } & \multicolumn{2}{|c|}{ False Positive Restrictive-Pattern, no. $(\%) \dagger$} \\
\hline & NHANES III & ARIC & NHANES III & ARIC \\
\hline GOLD & 96/344 (27.9) & $579 / 1,723(33.6)$ & $43 / 147(29.2)$ & $107 / 387(27.6)$ \\
\hline \multirow[t]{3}{*}{ ATS/ERS } & $24 / 268(9.0)$ & $119 / 1,256(9.5)$ & $58 / 167(34.7)$ & $142 / 452(31.4)$ \\
\hline & \multicolumn{2}{|c|}{ False Negative Airflow Limitation, no. $(\%) \ddagger$} & \multicolumn{2}{|c|}{ False Negative Restrictive-Pattern, no. (\%)§ } \\
\hline & NHANES III & ARIC & NHANES III & ARIC \\
\hline GOLD & $2 / 243(0.8)$ & $10 / 1,142(0.9)$ & $7 / 111(6.3)$ & $5 / 314(1.6)$ \\
\hline ATS/ERS & $1 / 243(0.4)$ & $30 / 1,142(2.6)$ & 2/111 (1.8) & $34 / 314(10.8)$ \\
\hline \multicolumn{5}{|c|}{$\begin{array}{l}\text { * Had airflow limitation by Global Initiative for Obstructive Lung Disease (GOLD) or American Thoracic Society/European Respiratory Society (ATS } \\
\text { lambda-mu-sigma (numerator) criteria. } \\
\dagger \text { Had restrictive-pattern by GOLD or ATS/ERS (denominator) criteria, but not by lambda-mu-sigma (numerator) criteria. } \\
\text { ‡ Did not have airflow limitation by GOLD or ATS/ERS (numerator) criteria, but had airflow limitation by lambda-mu-sigma (denominator) criteria. } \\
\S \text { Did not have restrictive-pattern by GOLD or ATS/ERS (numerator) criteria, but had restrictive-pattern by lambda-mu-sigma (denominator) criteria. }\end{array}$} \\
\hline
\end{tabular}

to LMS-based assessment, is clinically relevant in middleaged persons cannot be established by the present study. In particular, airflow limitation has no definitive "standard" against which comparisons can be made, and restrictive-pattern requires confirmation of reduced total lung capacity via body plethysmography or helium dilution.6,30,31 Consequently, future work should further evaluate the health outcomes of participants who had misidentified respiratory impairment with the GOLD and ATS/ERS criteria. This may require an analytical plan that avoids a spirometry-defined reference group for subsequent comparisons, pooling of several large cohorts to achieve an adequate power for analysis, and a larger array of health outcomes, including respiratory medication use and hospitalization. In addition, future work should evaluate whether LMS-defined restrictive-pattern more accurately predicts a reduced total lung capacity, relative to GOLD and ATS/ERS.

\section{Limitations}

First, the magnitude of the associations between respiratory impairment and mortality were not identical across the study samples, although the results were generally consistent and the differences could be due to sampling issues (eg, ARIC had a lower frequency of fair-to-poor health status and a lower mortality rate). Of note, greater consistency was found in the magnitude of associations between respiratory impairment and respiratory symptoms across the study samples.

Second, spirometry in NHANES III and ARIC was not specifically obtained after bronchodilator. Post-bronchodilator values may have had a minimal effect on our results, however, because study participants had high rates of smoking (conferring less reversible airway pathology) and because those who had self-reported asthma were excluded from the analytical sample.

Third, we studied only white middle-aged persons, and racial and age-group related differences can exist in pulmonary function. ${ }^{8,9,32}$ Although this does not impair the validity of our study, it does affect the generalizability.

Fourth, our study samples were assembled in the late 1980s and early 1990s and followed through 1988-2000, which raises the issue of the "timeliness" of the data, despite the likelihood of pulmonary physiology remaining stable over time. In view of these limitations, future work 


\section{LAMBdA-Mu-Sigma-Derived Z SCORE For Evaluating ResPiratory IMPairment}

should evaluate the clinical validity of LMS-defined respiratory impairment in more contemporary study populations, ${ }^{33}$ including other racial, ethnic, and (older) age groups, and with post-bronchodilator spirometry data.

\section{Conclusions}

Among white middle-age persons, LMS-defined airflow limitation and restrictive-pattern were significantly associated with mortality and respiratory symptoms. Consequently, an approach that reports spirometric values based on LMS-derived Z scores potentially provides an age-appropriate and clinically valid strategy for evaluating respiratory impairment.

\section{REFERENCES}

1. Thorne SL, Malarcher A, Maurice E, Caraballo R. Cigarette smoking among adults: United States, 2007. MMWR 2008;57(45):1221-1226.

2. Schindler C, Kunzli N, Bongard JP, Leuenberger P, Karrer W, Rapp $\mathrm{R}$, et al. Short-term variation in air pollution and in average lung function among never-smoker: the Swiss study on air pollution and lung diseases in adults (SALPADIA). Am J Respir Crit Care Med 2001;163(2):356-361.

3. Raherison C, Girodet P-O. Epidemiology of COPD. Eur Respir Rev 2009;18(114):213-221.

4. Murray CJL, Lopez AD. Evidence-based health policy. Lessons from the global burden of disease study. Science 1996;274(5288):740-743.

5. Rabe1 KF, Hurd S, Anzueto A, Barnes PJ, Buist SA, Calverley P, et al. The global strategy for the diagnosis, management, and prevention of chronic obstructive pulmonary disease. Am J Respir Crit Care Med 2007;176(6):532-555.

6. Pellegrino R, Viegi G, Brusasco V, Crapo RO, Burgos F, Casaburi $\mathrm{R}$, et al. Interpretative strategies for lung function tests. Eur Respir $\mathrm{J}$ 2005;26(5):948-968.

7. Meyer KC. Aging. Proc Am Thorac Soc 2005;2(5):433-439.

8. Stanojevic S, Wade A, Stocks J, Hankinson J, Coates AL, Pan H, et al. Reference ranges for spirometry across all ages. Am J Respir Crit Care Med 2008;177(3):253-260.

9. Stanojevic S, Wade A, Stocks J. Reference values for lung function: past, present and future. Eur Respir J 2010;36(1):12-19.

10. Hansen JF, Sun X-G, Wasserman K. Spirometric criteria for airway obstruction. Chest 2007;131(2):349-355.

11. Vaz Fragoso CA, Concato J, McAvay G, Van Ness PH, Rochester CL, Yaggi HK, Gill TM. Defining chronic obstructive pulmonary disease in older persons. Respir Med 2009;103(10):1468-1476.

12. Vaz Fragoso CA, Concato J, McAvay G, Van Ness PH, Rochester CL, Yaggi HK, Gill TM. Chronic obstructive pulmonary disease in older persons: a comparison of two spirometric definitions. Respir Med 2010;104(8):1189-1196.

13. Vaz Fragoso CA, Concato J, McAvay G, Van Ness PH, Rochester CL, Yaggi HK, Gill TM. The ratio of the forced expiratory volume in 1-second to forced vital capacity in establishing chronic obstructive pulmonary disease. Am J Respir Crit Care Med 2010;181(5):446-451.
14. Quanjer PH, Enright PL, Ruppel GL. The GOLD guidelines definition of mild airway obstruction. Respir Care 2010;55(10):1397-1399.

15. Cummings SR, Bates D, Black DM. Clinical use of bone densitometry: scientific review. JAMA 2002;288(15):1889-1897.

16. US Department of Health and Human Services. National Center for Health Statistics. Third National Health and Nutrition Examination Survey, 1988-94, NHANES III Laboratory Data File (CD-ROM), Public Use Data File Documentation Number 76200. Hyattsville, Maryland: Centers for Disease Control and Prevention; 1996.

17. Williams OD on behalf of the ARIC investigators. The atherosclerosis risk in communities (ARIC) study: design and objectives. The Am J Epidemiol 1989;129(4):687-702.

18. Miller MR, Hankinson J, Brusasco V, Burgos F, Casaburi R, Coates A, et al. Standardisation of spirometry. Eur Respir J 2005;26(2):319-338.

19. Becklake M, Crapo RO on behalf of the American Thoracic Society. Lung function testing: selection of reference values and interpretative strategies. Am Rev Respir Dis 1991;144(5):1202-1218.

20. Mannino DM, Buist AS, Vollmer WM. Chronic obstructive pulmonary disease in the older adult: what defines abnormal lung function? Thorax 2007;62(3):237-241.

21. Hankinson JL, Odencrantz JR, Fedan KB. Spirometric reference values from a sample of the general US population. Am J Respir Crit Care Med 1999;159(1):179-87.

22. Wheatcroft G, Cox CS, Lochner KA. Comparative analysis of the NHANES III public-use and restricted-use linked mortality files. Hyattsville, Maryland: National Center for Health Statistics; 2007.

23. Peduzzi P, Concato J, Feinstein AR, Holford TR. Importance of events per independent variable in proportional hazards regression analysis. II. Accuracy and precision of regression estimates. J Clin Epidemiol 1995;48(12):1503-1510.

24. SUDAAN language manual, release 9.0 Research Triangle Institute; 2004

25. SAS/STAT 9.2 user's guide. SAS Institute; 2008.

26. Gross NJ. Chronic obstructive pulmonary disease outcome measurements. Proc Am Thorac Soc 2005;2(4):267-271.

27. Cherry DK, Burt CW, Woodwell DA. National ambulatory medical care survey: 1999 summary. Advanced Data from Vital and Health Statistics 2001;322(July 17):1-36.

28. Qaseem A, Snow V, Shekelle P, Sherif K, Wilt TJ, Weinberger S, et al. Diagnosis and management of stable chronic obstructive pulmonary disease: a clinical practice guideline from the American college of physicians. Ann Intern Med 2007;147(9):633-638.

29. Celli BR, MacNee W for the American Thoracic Society and European Respiratory Society Task Force. Standards for the diagnosis and treatment of patients with COPD: a summary of the ATS/ERS position paper. Eur Respir J 2004;23(6):932-946.

30. Glady CA, Aaron SD, Lunau M, Clinch J, Dales R. Spirometrybased algorithm to direct lung function testing in the pulmonary function laboratory. Chest 2003;123(6):1939-1946.

31. Aaron SD, Dales RE, Cardinal PC. How accurate is spirometry at predicting restrictive pulmonary impairment? Chest 1999;(3):115:869-873.

32. Dransfield MT, Bailey WC. COPD: racial disparities in susceptibility, treatment, and outcomes. Clin Chest Med 2006;27(3):463-471.

33. Manolio TA, Weinmann GG, Buist SA, Furberg CD, Pinsky JL, Hurd SH. Pulmonary function testing in population-based studies. Am J Respir Crit Care Med 1997;156(3):1004-1010.

This article is approved for Continuing Respiratory Care Education credit. For information and to obtain your CRCE

(free to AARC members) visit www.RCJournal.com

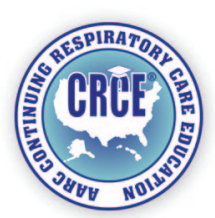

